\title{
New focus of active transmission of Chagas disease in indigenous populations in the Peruvian Amazon basin
}

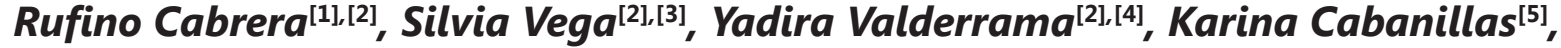 \\ Connie Fernández ${ }^{[2],[4],}$ Omar Rodríguez ${ }^{[6]}$, César Del Aguila ${ }^{[4]}$, Jesús Hernández ${ }^{[6]}$, \\ Leonardo Mendoza ${ }^{[7]}$ and Juan Ramón Meza ${ }^{[6]}$
}

\begin{abstract}
[1]. Grupo Temático de Enfermedades Metaxénicas, Dirección General de Epidemiología, Ministerio de Salud, Lima, Perú. [2]. Grupo de Trabajo de Enfermedad de Chagas en la Amazonia Peruana. Lima, Perú. [3]. Laboratorio de Leishmaniasis y Enfermedad de Chagas, Centro Nacional de Salud Pública, Instituto Nacional de Salud, Lima, Perú. [4]. Red de Salud Alto Amazonas, Dirección Regional de Salud Loreto, Yurimaguas, Perú. [5]. Centro de Salud de Saramiriza, Red de Salud Alto Amazonas, Dirección Regional de Salud Loreto, Saramiriza, Datem del Marañón, Perú. [6]. Centro de Salud de San Lorenzo, Red de Salud Alto Amazonas, Dirección Regional de Salud Loreto. San Lorenzo, Datem del Marañón, Loreto, Perú. [7]. Laboratorio de Entomología, Centro Nacional de Salud Pública, Instituto Nacional de Salud, Lima, Perú.
\end{abstract}

\begin{abstract}
Introduction: Several cases of acute Chagas disease (ACD) have been reported in the Peruvian Amazon basin. Methods: The objective was to describe and investigate $6 \mathrm{ACD}$ cases in children from indigenous Amazon communities in the province of Datem del Marañón in Loreto department (2006-2010). Results: The mean age was 3.6 years. All patients had fever, 4/6 hepatomegaly, 2/6 splenomegaly, and 5/6 had trypomastigotes of Trypanosoma cruzi on thick smears. The fatality rate was 33.3\%. Rhodnius pictipes and Rhodnius robustus adults were found inside the homes and in the peri-domiciles. Conclusions: All cases reported were isolated cases. We report a new focus of ACD in indigenous populations.
\end{abstract}

Keywords: Chagas disease. Indigenous population. Amazonian ecosystem. Peru.

One third of the 18 million people infected by Trypanosoma cruzi in Latin America develop Chagas disease, making it a very important public health problem ${ }^{1}$. Recently, an increasing number of acute cases of Chagas disease are being reported in Amazonian countries, either by vector transmission, as in Colombia $^{2}$ and Ecuador $^{3}$, or by oral transmission related to fruits and juices, principally in Brazil ${ }^{4}$.

In Peru, departments located in the Amazon basin or the Southwestern region are endemic for Chagas disease, as are those along the Northern Coast region ${ }^{5}$. The first case of acute Chagas disease (ACD) in the country was reported in 1919 from Madre de Dios department ${ }^{6}$ in the selva baja (below 400 $\mathrm{m}$ above sea level) in the Amazon basin, and it took another 34 years to detect 2 new ACD cases in 2 children from San Martín department, located in the selva alta $(1,000-4000 \mathrm{~m}$ above sea level) ${ }^{7}$.

After a silence of several decades, more ACD cases are now being reported in areas of the Peruvian Amazon basin without historical background. One case has been reported in the selva central in Pozuzo, Pasco department ${ }^{8}$, and another in Loreto

Address to: MSc. Rufino Cabrera. Grupo Temático de Enfermedades Metaxénicas/Dirección General de Epidemiología/MS. Calle Daniel Olaechea 199, Lima 11. Lima, Perú.

Phone: 511 631-4500 ext 130; Fax: ext 101, 140.

e-mail: rcabrerach@hotmail.com; rcabrera@dge.gob.pe

Received 08 July 2011

Accepted 29 July 2011 department in the selva baja ${ }^{5}$. Nevertheless, no cases had been reported within indigenous Amazon populations. Furthermore, information about the distribution of triatomines and infection by trypanosome parasites in the Peruvian Amazon basin is scarce.

The objective of this article is to describe clinical and epidemiological characteristics and to investigate $6 \mathrm{ACD}$ cases in children from populations of indigenous communities in the Peruvian Amazon basin within the province of Datem del Marañón in Loreto department, Peru (2006-2010).

The province of Datem del Marañón (DM), consists of 6 districts of Loreto department and is located in the northeastern Peruvian Amazon (Figure 1). It is included in the rainforest area of the eco-region. San Lorenzo is the capital city of the province and of Barranca district. The population includes indigenous and mestizo populations, including the Aguajun, the Huambiza, and the Kandozi. The indigenous communities are located on the banks of the Marañon River, and the main economic activities are agriculture and fishing. Plasmodium vivax and Plasmodium falciparum malaria, leishmaniasis, and soiltransmitted helminths are endemic in the region. The population lives mainly in rural areas (70.3\%) and only $2.4 \%$ have access to public water services inside or outside their homes.

The 6 ACD cases were detected between 2006 and 2010 by laboratory workers who were examining blood smears for malaria. A case of ACD reported in the community by the surveillance system was considered the index case and was defined accordingly, as described elsewhere ${ }^{5}$. 


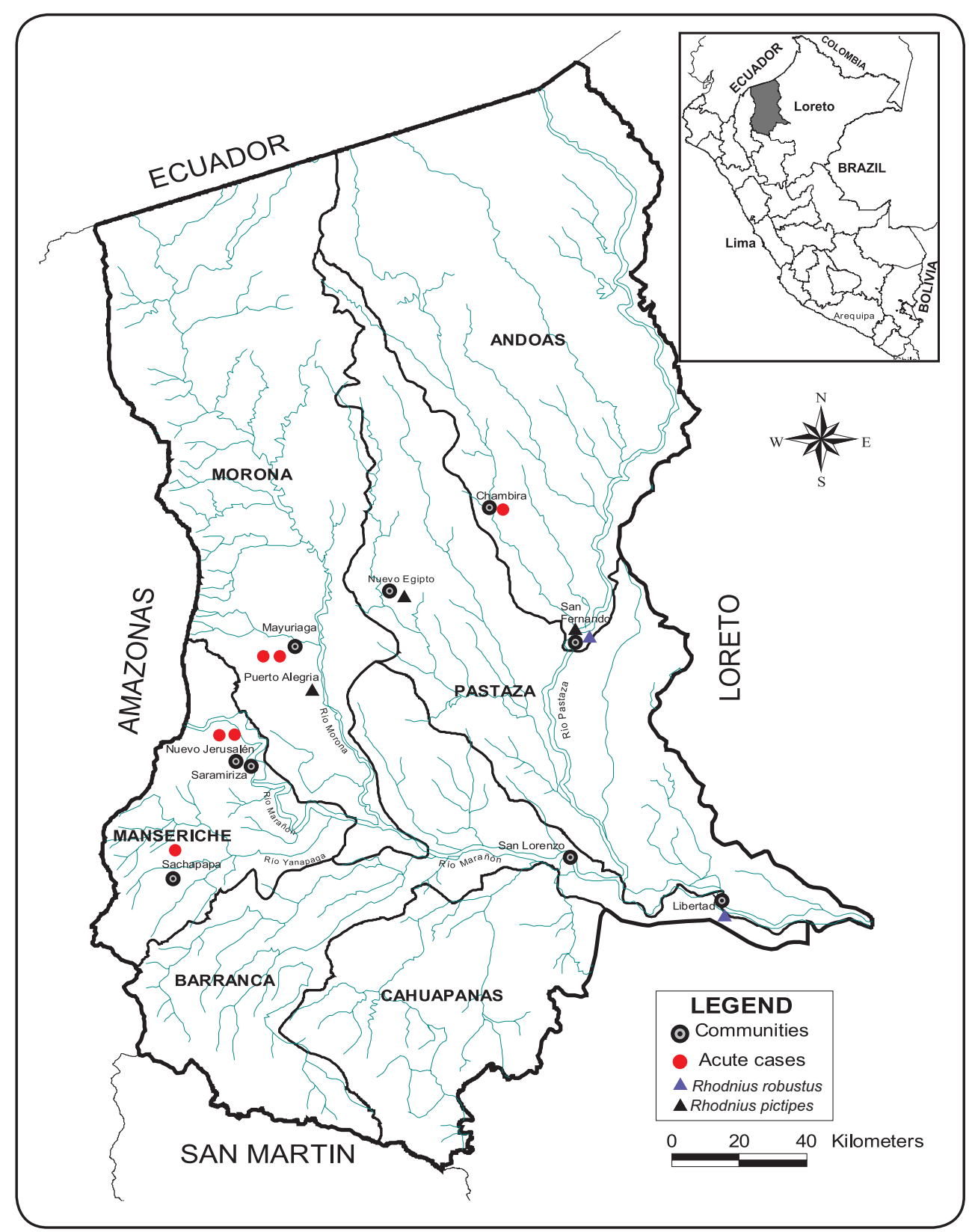

FIGURE 1 - Map of acute cases and geographic distribution of triatomines in Datem del Marañón province, Loreto, Peruvian Amazon.

The present study comprises a review of the investigation sheets and clinical files of the ACD cases reported. The parents and family relatives of the patients were interviewed with the help of a translator from the community, and serum samples were obtained for $T$. cruzi ${ }^{5}$ detection. Samples positive for Trypanosomes were further analyzed, and an entomologic evaluation was performed in patients' houses and surrounding areas. To identify collateral cases, blood samples were obtained according to the methods described elsewhere ${ }^{5,8}$, and serum samples were evaluated to detect anti-T. cruzi IgG antibodies with Chagatest ELISA recombinant v. 30, Wiener Lab $^{\circledR}$, and by indirect immunofluorescence (IIF) with a diagnostic titer value of 1:32. Only when both tests were reactive was a patient considered seropositive for T. cruzi infection. Patients with confirmed cases of ACD were offered treatment with benznidazole or nifurtimox according to the protocol of the Ministry of Health. The investigation was conducted with the approval of the $A p u$ (Chief) of each indigenous community.

The entomologic investigation was performed by manual collection according to the methods described elsewhere ${ }^{5}$. Live triatomines were transported to the laboratory for investigation of natural infection by Trypanosoma and taxonomic identification according to the key of Lent and Wygodzinsky9. Some dead specimens captured in the indigenous communities were also included in this report. Feces of live specimens were obtained by abdominal pressure, homogenized with saline solution, and observed under the microscope.

Clinic and epidemiologic aspects of the identified ACD cases (Table 1) and the results of the investigation of collateral cases are presented in the next section. 
TABLE 1 - Clinical and epidemiologic characteristics of acute Chagas disease cases in children from Amazon communities of indigenous populations in Datem del Marañón Province, Loreto, Peru (2006-2010).

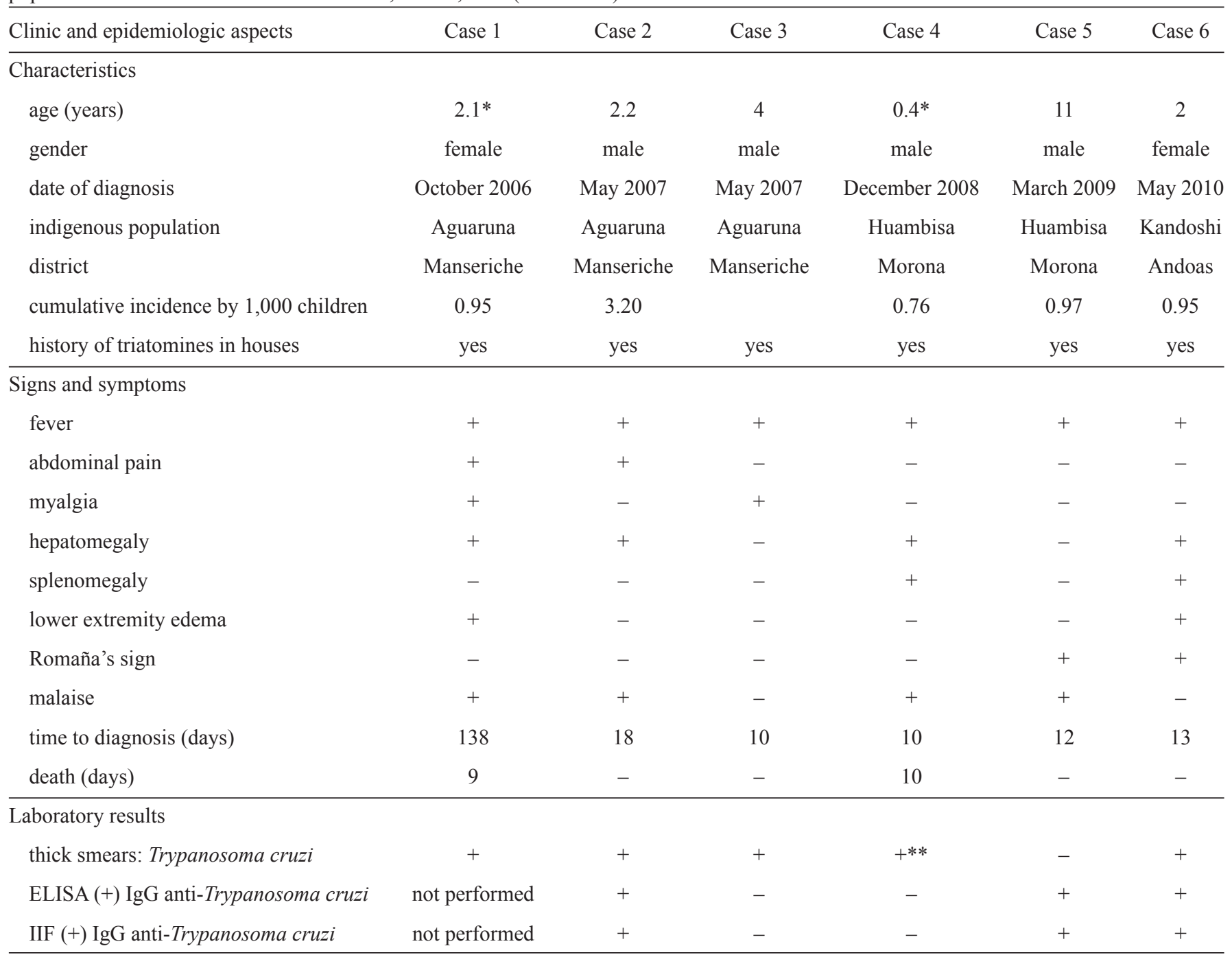

ELISA: enzyme-linked immunoabsorbent assay; IgG: immunoglobulin G; IIF: indirect immunofluorescence; *died 2/6 (33.3\%); **microconcentration technique was also performed.

\section{Case 1}

An indigenous resident from the community of Sachapapa, located $15 \mathrm{~h}$ by boat from the City of San Lorenzo, was evaluated on the third day of symptoms, presenting with nausea, vomiting, melena, and headache. On the fourth day, she was anorexic but thirsty. On day 5 , she developed temperature of $40^{\circ} \mathrm{C}$, with a heart rate of $98 / \mathrm{min}$, respirations $22 / \mathrm{min}$, and continued loss of appetite. A blood smear for $P$. vivax was reported as positive and treatment with chloroquine and primaquine was started, but it was stopped 2 days later because of the patient's unfavorable clinical evolution. During days 6 and 7, she had hematemesis, temperature of $41^{\circ} \mathrm{C}$, diminished consciousness, tonic-clonic movements in both arms and legs, lethargy, and generalized edema. The patient died 7 days after the first symptoms (Table 1).

Plasmodium was not detected in a blood smear sent to a hospital for quality control. Instead, Trypanosoma-like parasites were reported. The national reference laboratory in the
Instituto Nacional de Salud in Lima, Peru confirmed the presence of Trypanosoma cruzi trypomastigotes. In the month preceding the onset of symptoms the patient had not traveled outside her hometown or received blood transfusions. She was sleeping in open spaces only while her parents were performing agriculture activities. There was suspicion of an infestation of triatomines in the house, but it was impossible to interview the father and the mother because both committed suicide after their daughter's death. Available records indicated that the child was breast fed until 8 months and then received fruits and vegetables typical for the region such as chapo (mature banana cooked and smashed) and masato dulce, a sweet fermented beverage prepared of cooked manioc and cane juice. Her grandmother was the only relative available for evaluation, and she was negative for of T. cruzi antibodies.

\section{Case 2}

Indigenous residents of Nuevo Jerusalén, a small town of approximately 180 inhabitants (Figure 1) whose case histories 
began when a group of health workers reported 3 family members with fevers (patient, brother, and mother) and initiated a screen for malaria. Trypanosoma cruzi trypomastigotes were found in blood smears in Cases 2 and 3 (Table 1). Chagoma and Romaña's sign were absent and neither patient had a history of leishmaniasis, blood transfusion, or travel during the month prior to disease onset. At one point, the patient described in Case 2 had consumed masato in his regular diet. His mother had noticed kissing bugs that fed through the patient's skin and left redness and swelling at the bite sites. These kissing bugs were seen inside the family dwelling, which is made of pona palm trees. The parents breed dogs and hens. The patient was offered benznidazole, but abandoned treatment and was lost to follow-up. The mother, 28 years old, and the father, 39 years old were not reactive to T. cruzi antibodies.

\section{Case 3}

(Brother of patient from Case 2). His epidemiologic background is the same as Case 2. Chagoma was absent as were history of leishmaniasis or blood transfusions prior to disease onset. Masato was part of the diet. His disease onset was one week after that of Patient 2. At 7 days after symptom onset, a blood smear showed T. cruzi trypomastigotes, but ELISA and IIF tests were non-reactive (Table 1). The patient was offered benznidazole but abandoned treatment.

\section{Case 4}

An indigenous resident from the town of Mayuriaga (population about 150), located on the shores of the Mayuriaga River, affluent of the Morona River, was evaluated in a small health center on the fourth day after symptoms onset, and he was later transferred to a major health center because of worsening clinical status. On day 10 of symptoms, he arrived at the emergency room of the local health center with an apparent septicemia of abdominal focus, acute diarrheic disease, and febrile syndrome. He was tachycardic. Blood smear was positive for $T$. cruzi trypomastigotes (6-10 per high power field). He died the same day. His parents refused necropsy. The parents denied consumption of fruit juices or any travelling outside his hometown during the month prior to symptoms onset (Table 1). The family dwelling was made of pona palm trees, and a palm tree is located at a distance of approximately 30 meters from the dwelling. His parents breed hens. The patient used to sleep in a hammock without mosquito nets. Both parents and 8 relatives were seronegative in tests for Chagas disease.

\section{Case 5}

Was detected during the epidemiologic investigation of Case 4. On the $12^{\text {th }}$ day of the disease outbreak, this patient's clinical examination was positive for 1 week of subjective fever and chagoma. No adenopathy was noted. The patient denied blood transfusion, leishmaniasis, or recent travel. He was the only person in his family who slept without mosquito nets. He recognized triatomines by the name of chinchi in the Huambiza dialect (Table 1). He was treated with nifurtimox for 60 days before he was lost to follow-up. The family breeds hens. His mother and 5 brothers were negative for $T$. cruzi antibodies in serum samples.

\section{Case 6}

Indigenous resident from the town of Chambira on the shores of the Huitoyacu river, affluent of the Pastaza River (Figure 1). The case was detected in a private drugstore in San Lorenzo City, 11 days after symptoms onset. T. cruzi trypomastigotes were found in 2 blood smears (Table 1). The patient's parents recognized triatomines by the name of punduna in Kandozi dialect. The fever lasted for approximately 3 weeks. Clinical examination was positive for facial edema and rash, but negative for chagoma. Antecedent history was negative for leishmaniasis, blood transfusions, or traveling within 4 weeks of disease onset. Two weeks before, she had played on the farm with her siblings. Masato dulce and chapo (mature banana) are part of her usual diet. She was treated with nifurtimox. Her father and one brother were positive for T. cruzi antibodies in serum samples. The mother was negative.

The results of the entomologic investigation are shown in Figure 1 and Table 2. No triatomines were found in the dwellings investigated.

We are reporting for the first time a new focus of active transmission of Chagas disease in the Peruvian Amazon basin among populations of indigenous communities, including the Aguajun in Manseriche, the Huambiza in Morona, and the Kandozi in Andoas. A probable case of Chagasic cardiomyopathy has also been reported in an adult from Yurimaguas with history of travel to San Martín ${ }^{10}$, and a serum positive Kandozi case and 2 Shawi cases in the Alto Amazonas province have been reported. The districts where these individuals may have been

TABLE 2 - Sylvatic triatomines in indigenous communities from the Datem del Marañón Province, Loreto, Peruvian Amazon.

\begin{tabular}{|c|c|c|c|c|c|}
\hline District & Locality & Species & Infested house & Date of collection & Area of collection \\
\hline Barranca & Libertad & Rhodnius robustus( $\left({ }^{\Uparrow}\right)$ & $1 *$ & November 2007 & bedroom \\
\hline Pastaza & Nuevo Egipto-Río Chapuri & Rhodnius pictipes $(\lesssim)$ & $1^{*}$ & April 2010 & bedroom \\
\hline \multirow[t]{2}{*}{ Morona } & Puerto Alegría & & & & \\
\hline & $\left(\mathrm{LS} 04^{\circ} 19^{\prime} 41.4^{\prime \prime}\right.$, LW $\left.077^{\circ} 12^{\prime} 57.91^{\prime \prime}\right)$ & Rhodnius pictipes $(\uparrow)$ & $1 / 77$ & May 2009 & bedroom \\
\hline & & Rhodnius robustus** (ठ) & $1 / 18$ & June 2010 & kitchen (wall) \\
\hline
\end{tabular}

*Specimen captured by a family member; ** Metacyclic trypomastigotes were observed in triatomines feces. 
infected are not mentioned ${ }^{11}$. The specific cumulative incidence was highest in Manseriche.

Between 1987 and 1989, in Ecuador's Amazon region, 2 ACD cases were described in the indigenous Quechua population in a 10-case series ${ }^{3}$. The ACD focus we present in this study shows more intense active transmission than reported in Pozuzo (Pasco department) in the selva central ${ }^{8}$ or in the rural area of Loreto department, where sporadic transmission has been reported ${ }^{5}$. Instead the areas mentioned in the present study resemble high transmission areas in the basin of the Utcubamba River $^{12}$, located in the upper part of the Marañon River, where the main vector, Panstrongylus herreri, resides ${ }^{13}$.

Before 2005, Datem del Marañón province was be part of Alto Amazonas province, in Loreto department. It has been reported there that Panstrongylus geniculatus, Rhodnius pictipes, and Rhodnius robustus are present ${ }^{14}$. We have found $R$. robustus in the Barranca and Andoas districts. In Andoas, the insect was infected with metacyclic trypomastigotes, similar to trypanosomatids. $R$. pictipes has been reported in the districts of Morona, Pastaza, and Andoas. All samples were adult forms collected inside houses. Further investigations applying appropriate methods to detect species involved in human transmission and to identify natural infection rates are urgently needed.

The total fatality rate in this series was higher than that reported in Ecuador ${ }^{3}$ and in Brazilian Amazonia ${ }^{4}$. This may be explained by the comorbidities that presented with these cases. One patient presented with acute diarrheal disease and another with a febrile hemorrhagic syndrome. Young age and rapid access to health centers may also account for different fatality rates. Of $233 \mathrm{ACD}$ cases reported in the Amazonian Region of Brazil, 13 patients died. Half of them presented with myocarditis and 1 was associated with cerebral malaria ${ }^{4}$.

Fever was the most important symptom in our case series, as in other cases reported in indigenous and colonial populations in the Peruvian Amazon basin ${ }^{5,7,12}$, Ecuador ${ }^{3}$, Colombia ${ }^{2}$, and $\mathrm{Brazil}^{4}$. Frequency of hepatomegaly was similar to other acute cases from Brazilian Amazonia ${ }^{4}$, but different from the cases reported in Ecuadorian Amazonia ${ }^{2}$. Entry signs were also very rare in our series, with similar results in Ecuador ${ }^{2}$ and Brazil ${ }^{4}$. Some specific signs of ACD in the Amazonia were face and lower extremity edema ${ }^{4}$, which were present in 2 cases. Based on the above clinical findings, it is important to study in more detail and with more cases the clinical characteristics of ACD cases in the Amazon basin.

The limitations of this report include the lack of identification of the infection focus, although we performed a comprehensive outbreak investigation. Trypanosoma rangeli does not produce fever, which differentiates its clinical manifestations from those presented in our cases. Case 5 was the only patient with both negative blood smear and micro-concentration test, but he had a clinical picture compatible with ACD and was positive for T. cruzi antibodies. In future investigations, it would be desirable to have rapid access to molecular tests for T. cruzi identification, especially DNA tests.
All cases reported in this paper were isolated cases and autochthonous from the Amazonian region, and it is very likely that transmission was by the vectors found in these towns. However, oral transmission cannot be ruled out, especially in Cases 2 and 3, in whom symptoms onset were only one week apart. In these cases, the consumption of masato as a beverage may had been involved in the transmission.

Children of indigenous Peruvian populations have high morbidity and mortality rates ${ }^{15}$. In areas of active transmission they are vulnerable to ACD with a high risk of death because of comorbidities, early age of infection, late disease diagnosis, and poor nutrition status. Therefore, early detection of ACD in febrile patients with negative blood smears for malaria may be a suitable strategy to diminish lethality in this group.

\section{ACKNOWLEDGMENTS}

The authors thanks Dr. Aquiles Vilchez, Dr. Juan Arrasco, Dr. Manuel Espinoza, Dr. Giovanni Cabrera, Enrique Purisaca, Edilso Torres, Pablo Villaseca, María Teresa Santa Cruz, and Carlos Mori for their support in field and laboratory case investigation, and Alvaro Whittembury, Luis A. Marcos, and Elizabeth Sanchez for editorial assistance.

\section{CONFLICT OF INTEREST}

The authors declare that there is no conflict of interest.

\section{FINANCIAL SUPPORT}

This research was supported by Dirección General de Epidemiología of the Ministry of Health (Peru), Instituto Nacional de Salud (Peru), and Red de Salud Alto Amazonas.

\section{REFERENCES}

1. Teixeira ARL, Nitz N, Guimaro MC, Gomes C, Santos-Buch CA. Chagas disease. Post Med J 2006; 82:788-798.

2. Nichols RS, Cucunubá ZM, Knudson A, Flores AC, Montilla M, Puerta $\mathrm{CJ}$, et al. Enfermedad de Chagas aguda en Colombia, una entidad poco sospechada. Informe de 10 casos presentados en el periodo 2002 a 2005. Biomédica 2007; 27 (supl 1):8-17.

3. Amunárriz UM, Chico HME, Guderian HRH. Chagas disease in Ecuador: a sylvatic focus in the Amazon region. J Trop Med Hyg 1991; 94: 145-149.

4. Pinto AYN, Valente SAS, Valente VC, Ferreira GAJR, Rodrigues CJ. Fase aguda da doença de Chagas na Amazônia brasileira. Estudo de 233 casos do Pará, Amapá e Maranhão observados entre 1988 e 2005. Rev Soc Bras Med Trop 2008; 41:602-614.

5. Cabrera R, Vega S, Cáceres AG, Ramal CA, Álvarez C, Ladera P, et al. Epidemiological investigation of an acute case of Chagas disease in an area of active transmission in Peruvian Amazon region. Rev Inst Med Trop São Paulo 2010; 52:269-272.

6. Escomel E. La trypanosomiase humaine existe dans les forêts orientales du Pérou. Bull Soc Pathol Exotique Paris 1919; 12:723-726.

7. Lumbreras H, Arrarte J, Guevara B. Primeros casos de la enfermedad de Chagas en el Departamento de San Martín. Rev Med Per 1955; 26 : $42-47$. 
8. Vega S, Mendoza A, Cabrera R, Cáceres GA, Campos E, Ancca J, et al. Primer caso de enfermedad de Chagas aguda en la Selva Central del Perú: Investigación de colaterales, vectores y reservorios. Rev Peru Med Exp Salud Publica 2006; 23:288-292.

9. Lent H, Wygodzinsky PW. Revision of the Triatominae (Hemiptera, Reduviidae), and their significance as vectors of Chagas' disease. Bull Am Mus Nat His 1979; 163:125-520.

10. Falconí RE. Enfermedad de Chagas en Alto Amazonas-Loreto: primer caso. Rev Farmacol (Lima) 1997; 5:90-91.

11. Lumbreras H. El problema de la Enfermedad de Chagas en los diferentes departamentos del Perú. Rev Vier Med 1972; XXII:43-77.
12. Herrer H, Morales J. Trypanosomiasis americana en el Perú. VI. Verificacion de la enfermedad de Chagas en la cuenca del Marañón. Rev Med Exp 1955; 9:83-101.

13. Cuba-Cuba C, Abad-Franch F, Roldán RJ, Vargas VF, Pollack VL, Miles MA. The triatomines of northern Peru, with emphasis on the ecology and infection by trypanosomes of Rhodnius ecuadoriensis (Triatominae). Mem Inst Oswaldo Cruz 2002; 97:175-183.

14. Guillén Z, Cáceres I, Elliot A, Ramírez J. Distribución geográfica de los triatominos en el oriente del Perú. Rev Peru Med Trop UNMSM. 1992; 6:93-97.

15. Montenegro RA, Stephens C. Indigenous health in Latin America and the Caribbean. Lancet 2006; 367:1859-1869. 